\title{
¿A DÓNDE VAS? \\ LA MARGINALIDAD Y EL FRACASO COMO TEMAS LITERARIOS
}

\author{
Felipe Osorio \\ Universidad del Valle
}

\section{I}

La obra de Tim Keppel (1955) está compuesta por los libros de cuentos Alerta de terremoto (2002) y ¿A dónde vas? (2015), finalista del segundo premio Biblioteca de Narrativa Colombiana; y por la novela Cuestión de familia (2009). Además de los libros, el escritor norteamericano -radicado en Cali hace más de 20 años- ha sido publicado en diversas revistas literarias y culturales de Colombia como El Malpensante, Número, Arcadia, El Espectador, entre otras; y en revistas literarias y antologías de cuentos en los Estados Unidos.

La ilustración de Paula Gutiérrez -que sirve de portada de ¿A dónde vas? - presenta la figura un tanto opaca de un hombre (tomada con la técnica de desenfoque de una cámara fotográfica) que camina por un sitio sin pavimentar bordeando una pared mohosa y manchada. El libro se compone de 15 cuentos, cuyas diégesis transitan por ambos hemisferios de América (semejando el periplo vital del escritor). De esta forma, la serie que se titula Norte constituye la primera y tercera parte del libro (3 y 4 cuentos, respectivamente) y la serie Sur, la segunda y cuarta parte (4 cuentos cada una). Los cuentos de Norte transcurren en Estados Unidos, especialmente en Filadelfia; los del Sur, en Colombia, principalmente en Cali. No obstante, la división geográfica de los cuentos no genera una diferencia en la construcción de los personajes del libro, que aquí y allá son seres opacos -como el de la portada- que recorren la cuesta abajo de sus vidas. La temática del fracaso se cierne en cada uno de los relatos que componen este libro de cuentos. En "La Cima", asistimos a la historia de Doug, un gringo que "llegó [a Cali] como viajero y se quedó trabajando como fotógrafo" (202). En esta ciudad empezó a frecuentar el bar La Cima "fascinado y entretenido 
por el zoológico de personajes" (202) que se daban cita por las noches. El lugar se compone diariamente de un grupo de poetas, artesanos, músicos, fotógrafos, etc, que se encuentran para recordar con nostalgia la Caliwood de la década de los 70. El mayor logro que algunos de ellos blanden es haber conocido a Andrés Caicedo, "el ídolo literario de la ciudad que se suicidó a los veinticinco" (202). En la compañía de estos personajes, y al calor de los tragos, el bareto y el perico, Doug aliviana el duelo por el divorcio de su esposa. Por otra parte, en el relato "El puente", Julio salva la vida de Mónica, una prostituta de origen nariñense que quiere acabar con su soledad tirándose de un puente. Cuando conoce a Mónica, él atraviesa el duelo por la muerte de su única hija. Empiezan entonces una relación en la que cada uno le ofrece un nuevo propósito en la vida del otro.

En ambos relatos -y en los otros que componen este libro- vemos cómo los personajes tejen lazos de afecto y solidaridad similares a los que se pueden construir en una terapia de grupo. No obstante, las narraciones no se ocupan de juzgar desde un pedestal moral el fracaso de sus vidas (como ocurre en La Virgen de los sicarios), sino de apreciar la humanidad que germina en dicha condición. En "Amor en el metro", el narrador realiza la siguiente descripción del Metro de Filadelfia:

De acuerdo, era sucio y lleno de grafitis y olía a orines. Estaba repleto de desamparados que dormían en cajas, pero había una especie de sentimiento fraternal ahí abajo, una humanidad compartida. Eso no se encuentra en un taxi o un carro. Se podía ver todo tipo de gente, hablando idiomas diferentes, maldiciendo y rezando, y profesando su amor; había ucranianos y rastafaris, harlistas y bailarinas, prostitutas y gente con letreros ambulantes que decían ¡ARREPIÉNTANSE! Y todos los viernes, un travesti de dos metros tocaba Nacida libre en un corno francés. (31)

\section{II}

En un documental producido por Señal Colombia, el autor cuenta brevemente que después de su graduación trabajó por un tiempo con gente desamparada de Filadelfia (sur de Estados Unidos). Dicha experiencia le permitió estar en las "entrañas de la sociedad: 
drogadicción, violencia, sufrimiento, prostitución". En este mismo sentido, Keppel viajó por diferentes ciudades de los Estados Unidos trabajando como taxista, camarero, librero, empacador de gaseosa y cantinero. En todos ellos pudo conocer "historias sencillas del común del hombre medio norteamericano" (Kremer, sin número de página) y, sobre todo, descubrir esa ciudad marginal que es la misma en el Norte y en el Sur. La experiencia de descubrir el mundo con los ojos de forastero se traslada a sus cuentos. En estos se puede reconocer una necesidad de escrutar hasta los mínimos recodos de esa exultante ciudad:

Ves gente de la calle por todas partes. Dormidos en los andenes, acurrucados al lado de los basureros, boxeando con su sombra en medio de la calle. Abres un dispensador de periódicos y encuentras una reserva de objetos personales: pantalones, zapatillas, una cuchilla desechable. Y de la nada, las delgadas y tintineantes notas del camión de los helados haciendo sus rondas de bloque en bloque: "Merrily, merrily, merrily, merrily. Life is but a dream" (21)

Contrario a la intención de narrar con el mínimo detalle la ciudad, al autor no le interesa describir lo que ocurre en el interior de los personajes; por el contrario, elige ciertas acciones y situaciones, generalmente cotidianas, que representan los movimientos telúricos que ocurren en el interior de estos y que ellos mismos, en algunos casos, desconocen. Es el caso de Lou, un gringo que vive hace veinte años en Colombia, trabaja en el Ciat, es divorciado y tiene una hija. Lou se ha permitido el esfuerzo de comprar caviar para celebrar el momento en el que una editorial le publique su libro Agricultura tropical en el siglo XXI (ya ha sido rechazado por varias editoriales), al que se ha dedicado los últimos diez años. Al llegar a su casa luego de ir con su hija de pesca, abre el caviar y se lo come con ella, acompañado de tostaditas y ron. Sin necesidad de decirlo, sabemos la ruptura que genera tal situación al interior del personaje: la aceptación de la no publicación de su libro, su fracaso como académico y la imposibilidad de ganarse la admiración de su hija. 
En "Se veían hasta las cosas más minúsculas" (Carver, 1981), Nancy despierta por un ruido que oye en la verja que separa su casa de la de su vecino, Sam Lawton. Antes de pararse de la cama a cerrar la verja, observa a su marido con la claridad que le ofrece una luna que esa madrugada es particularmente potente y revela "hasta las más minúsculas cosas". A su lado ronca su marido, con la boca abierta, las manos sobre el pecho pálido, ocupando tres cuartas partes de la cama. Bajo esa luna que lo ilumina todo, Nancy camina en bata hacia la verja y tiene una pequeña charla con su vecino, que la coge del brazo fuertemente y la lleva a los arbustos -ella no opone resistencia- para mostrarle cómo está matando una plaga de babosas, que amenaza con comerse su jardín. Aunque no ocurre nada más que una normal conversación entre vecinos, después de la cual Nancy vuelve a cama con su marido, todo ha sido revelado en su interior: el tedio que a la protagonista le produce su desaliñado y desconsiderado esposo, y el deseo que siente de transgredir esa verja que la separa de su vecino y que, para cerrar con broche de oro un cuento perfecto, recuerda no haber cerrado cuando se acuesta de nuevo.

Este procedimiento carveriano de socavar en las profundidades del relato a través de la historia que está en la superficie -que se ha representado con la metáfora del Iceberg y que tiene como sus más ilustres representantes a Chejov y a Hemingway- es axial en el proyecto narrativo de ¿A dónde vas? En "Comején", vemos cómo una plaga de este bicho está devorando la cama de John y Sandra, una pareja que tiene diferencias con respecto a la posibilidad de tener hijos. A medida que la relación se desmorona, la casa va siendo consumida por el insaciable comején. Al terminar la relación, Sandra se marcha de la ciudad y John se da a la tarea de eliminar el bicho y reconstruir su casa (la casa era solo de él). Tiempo después, cuando ella pasa a recoger sus cosas, se sorprende al ver que John ha conseguido eliminar el bicho y reconstruir la casa. El cuento concluye con los protagonistas en la alcoba mirando la cama "más grande [y bella] que la anterior" (83) y "con las manos casi tocándose". Por su parte, en "Consentimiento 
implícito" asistimos a un momento crucial en la vida de un joven librero de Filadelfia: ha sido sorprendido conduciendo borracho y para evitar la cárcel debe asistir "todos los lunes por la noche, durante diez semanas" (41) a un curso para conductores ebrios. En algún momento del curso, la profesora les explica a los infractores que cuando vuelvan al volante tendrán un consentimiento implícito. Esto significa que "implícitamente han aceptado la responsabilidad por su sobriedad..." (44). Además, les indica que para graduarse tendrán que llevar a una persona conocida a la ceremonia de grado. Trey ha empezado a salir con Joy, cuyo tema favorito es "poner su vida en orden" (56). Joy detesta el licor, pues tiene "un historial de borrachos buenos para nada, entre ellos su padre" (46). Por esa razón, Trey finge que no le gusta la bebida y le oculta lo ocurrido. Al finalizar la historia, Trey se ve obligado a contarle a Joy y llevarla a la ceremonia, pues nadie más lo acompaña. Contrario a lo que piensa, cuando recibe el diploma y da vuelta para observar a su novia, en lugar de un rostro furioso, ve "la radiante sonrisa de una novia sonrojada" (60).

En ambas historias, la anécdota se teje en función de exponer lo que ocurre al interior de los personajes. Así, el comején en la cama de John y Sandra es metáfora del deterioro de la vida sexual y sentimental de la pareja, y la posterior reconstrucción de la casa, de la reedificación interior de John; en el otro cuento, la invitación a la ceremonia de graduación que Trey hace a Joy simboliza el consentimiento implícito de una nueva vida de pareja, en la que ha quedado atrás el licor. En este mismo sentido, los objetos de la realidad representan lo que pasa al interior de ambas relaciones. De esta manera, Sandra encuentra el certificado matrimonial devorado por la plaga en el momento más tenso de su relación con John. Por su parte, en "Consentimiento implícito", mientras Trey termina de pintar el cuarto de Joy -que un exnovio empezó-, ella le sujeta la escalera y le da la estabilidad necesaria para que no se caiga y pueda concluir lo que el novio anterior ha dejado sin terminar.

Recogiendo lo anterior, es preciso señalar que las historias que componen ¿A dónde vas? no se ocupan de seres humanos exitosos y con el control de sus vidas; tampoco versan estas páginas sobre 
anécdotas increíbles, de esas que rara vez suceden al hombre común. Es esa la gran virtud del autor y lo que lo emparenta con la gran tradición del cuento norteamericano del siglo XX: Keppel sabe que los sismos interiores ocurren cuando se destapa una lata de comida o se sostiene una conversación cotidiana con un vecino. La función de su literatura no es, pues, ofrecer espejismos sobre la realidad, sino develar la belleza simple y sin maquillaje de los seres humanos.

\section{Referencias Bibliográficas}

Keppel, T. (2015) ¿A dónde vas? Bogotá: Alfaguara.

Kremer, H. Alerta de terremoto de Tim Keppel. Recuperado de https:// bibliotecadigital.icesi.edu.co/biblioteca_digital/bitstream/10906/65466/1/ alerta terremoto.pdf

Letra Urbana. (Señal Colombia). (2013) Documental Tim Keppel. De https:// www.youtube.com/watch? $=\mathrm{gHdD} 4 \mathrm{aDA} 7 \mathrm{AI}$ 